\title{
La difusión de la pedagogía del jardín infantil (Antecedentes de la educación inicial en Nicaragua)
}

Ileana Gadea Rivas

Recepción: 25 - 07 - 2015 / Aceptación: 20 - 12 - 2015

\section{Resumen}

El objetivo de la investigación ha sido analizar el proceso a través del cual se comenzó a implementar en Nicaragua la pedagogía del jardín infantil. De esa manera se espera contribuir al conocimiento acerca de los antecedentes de la educación inicial. La metodología de investigación consistió en la consulta de archivos y el análisis de fuentes documentales y bibliográficas de acuerdo con Severino (2008). Las fuentes utilizadas comprendieron biografias, correspondencia, fotografias, informes educativos y estudios sobre la historia de los jardines infantiles. Los resultados indican que a fines del siglo XIX, en el contexto histórico de difusión internacional de los jardines infantiles, profesoras de Estados Unidos aplicaron por primera vez dicha pedagogía en el campo de la educación inicial y de la enseñanza para la docencia en el Colegio de Señoritas de Granada. Esta experiencia se nutrió del movimiento de difusión internacional y a la vez generó un proceso de enseñanzaaprendizaje y difusión en el país. Por lo tanto, existe una relación significativa entre el desarrollo de la educación inicial en Nicaragua y dicho movimiento internacional.

Palabras claves: Difusión internacional de los jardines infantiles, historia de la educación inicial en Nicaragua.

\begin{abstract}
The purpose of this study has been to analyze the process through which kindergarten pedagogy was first introduced in Nicaragua. The study aims at contributing to a better understanding of the history of preschool education. The methods involved archival research and bibliographic and document analysis according to Severino (2008). Documentary sources, such as biography, educational reports, letters, photographs, as well as studies about the history of the kindergarten, were consulted. The results indicate that, at the end of the $19^{\text {th }}$ century, kindergarten pedagogy was first introduced and implemented in Nicaragua in the field of preschool education and teacher training by teachers from the United States at the Young Ladies College of Granada. This process received the influence of the international context of diffusion of the kindergarten and at the same time generated a process of diffusion, teaching and learning in Nicaragua. Therefore, there is a link between the developments of preschool education in Nicaragua with the international kindergarten movement during the second half of the $19^{\text {th }}$ century.
\end{abstract}

Keywords: History of preschool education in Nicaragua, international diffusion of the kindergarten. 


\section{Introducción}

Friedrich Froebel, creador del "kindergarten" (en alemán significa jardín infantil), se dedicó a la tarea de difundir su propuesta pedagógica para que ésta llegara a formar de la educación de niños y niñas y de la enseñanza para la docencia. A través de diversas estrategias, este educador llamó la atención sobre la importancia de la educación de los seres humanos desde sus primeros años de vida. También abogó para que hombres y mujeres, pero especialmente las mujeres, contribuyeran a su proyecto como docentes. Desde mediados del siglo XIX, estudiantes y familiares se unieron a esa labor. Con sus gestiones y trabajo educativo se inició un proceso de difusión de la pedagogía de los jardines infantiles que llegaría a tener alcance internacional. Sin ese proceso, no habría sido posible que a fines del siglo XIX dicha pedagogía se pusiera en práctica en el Colegio de Señoritas de Granada.

Los estudios sobre la trascendencia del jardín infantil y su proyección han destacado el movimiento de difusión. Allen (1989) ha documentado un movimiento de defensa de los jardines infantiles en los estados alemanes $\mathrm{y}$ en Estados Unidos desde mediados del siglo XIX. Brehoney ha analizado su establecimiento en colonias británicas de África y Wollons (2000) un movimiento global de difusión desde fines del Siglo XIX. Por medio de once estudios de casos, esta autora y colaboradoras han analizado el proceso de implementación de la pedagogía de los jardines infantiles en Australia, China, Estados Unidos, Inglaterra, Japón, Palestina, Polonia, Rusia, Turquía y Vietnam. Wollons clasifica las formas de introducción del jardín infantil en primarias, secundarias y terciarias según su distancia con respecto al modelo original de Froebel. Aunque su estudio se presenta como global, no incluye países de América Latina y del Caribe.

Con el objetivo de responder a la pregunta acerca de cómo se introdujo por primera vez la pedagogía del jardín infantil en Nicaragua, este trabajo ha estudiado dicho proceso enfocándose en el contexto del movimiento de difusión de los jardines infantiles. De esa manera, el estudio incorpora la dimensión internacional a las consideraciones del contexto de Nicaragua que han sido estudiadas por Peralta (2009).

La metodología consistió en una investigación bibliográfica y el análisis documental de acuerdo con los criterios de Severino (2008). Como punto de partida para la investigación, se han consultado los escritos de Toledo de Aguerri, considerada pionera de la educación inicial nicaragüense, su biografía escrita por López Miranda (1988) y la investigación de Peralta (2009) sobre los primeros jardines infantiles en América Latina, obra que estudia la experiencia de Argentina, Chile y Nicaragua.

El presente artículo está organizado en tres secciones. En primer lugar se presenta un esbozo acerca de la difusión de la pedagogía del jardín infantil iniciada por Froebel desde mediados del siglo XIX, la difusión internacional desde Europa a diferentes países a mediados del siglo XIX y su introducción e implementación en Nicaragua a fines del siglo XIX y por último, se exponen las conclusiones.

Con este estudio se espera contribuir al conocimiento sobre los antecedentes de la educación inicial, tema de gran importancia considerando el lugar prioritario que ésta ocupa en el Plan Estratégico de Educación 2011-2015, la Política Nacional de Primera Infancia y el Plan Nacional de Desarrollo Humano 2012-2016. Una perspectiva más amplia de las raíces de la educación inicial puede ayudar a una mejor comprensión, favorecer la reflexión y mejorar la práctica. También puede contribuir conocimientos útiles sobre el devenir de la profesión docente en educación inicial para quienes la ejercen o se están preparando para ejercerla. 


\section{La difusión de la pedagogía del jardín infantil iniciada por Froebel}

La difusión de la pedagogía del jardín infantil para bien de la humanidad constituye una idea central en la visión del proyecto educativo de Friedrich Froebel (1782-1852). Para expresar que su obra alcanzaría a muchas generaciones, el utilizó la parábola del Evangelio sobre la pequeña semilla de mostaza, que como el reino de los cielos, crece y desarrolla grandes ramas donde descansan las aves. De igual forma, bajo las ramas de su proyecto educativo iba a "descansar la infancia y su descendencia en alegría y paz. Marcos iv, 31-32" (Michaelis y Moore: 1891; 133). Por lo tanto, Froebel se proponía establecer un ámbito de bienestar para la infancia y trascender el contexto de su localidad y su época. Esto implicaba la difusión internacional y la educación de docentes que la desarrollaran.

Este educador forjó su sistema para la educación y la atención de la niñez y la enseñanza para la docencia con base en la unidad y la actividad, principios que él creía universales. A través de la reforma que proponía, el intentaba transformar la educación, la familia y la sociedad. La formación integral acorde a las etapas del desarrollo, la naturaleza, el juego y el trabajo manual como fuente de enseñanza eran elementos fundamentales de la pedagogía que consideraba aplicable a todas las clases sociales. Influido por reflexiones naturalistas, idealistas y románticas y con base en la pedagogía de Comenio y Pestalozzi, Froebel planteó los fines del jardín infantil, elementos clave de su filosofía de la educación: el restablecimiento del vínculo entre la vida de la niñez y la vida de las mujeres y el cultivo del potencial de la humanidad desde la infancia. El logro de esta obra significaba cumplir con los mandamientos y contribuir a la unidad entre los seres humanos, Dios y la naturaleza, según las ideas krausistas y el cristianismo con que Froebel se identificaba.
Conforme a los objetivos de su reforma, Froebel fue un activo divulgador de su pedagogía, preparó instrumentos e impulsó estrategias de difusión. Se dedicó a impartir clases acerca de su método y brindar asesoría a través de visitas y correspondencia. Asimismo, organizó los dones (materiales de aprendizaje diseñados para la manipulación y exploración) y ocupaciones (actividades manuales como el modelado en barro, el dibujo, tejido con papel) como recurso didáctico, explicó la teoría que los fundamentaba y la manera en que debían utilizarse (Morrison: 2005; 65). También expuso recomendaciones sobre la organización de las aulas y otros espacios educativos para el juego al aire libre y el cultivo de parcelas donde niñas y niños pudieran estar activos, conocer su vocación y desarrollar su potencial, entrar en contacto con la naturaleza y en unidad con Dios (Michaelis y Moore: 1891; 94). Para apoyar la enseñanza en el hogar y en centros educativos, escribió y publicó libros y boletines; por ejemplo, los Cantos y Caricias Maternales y las Hojas Dominicales. En estas obras se pronunció en favor de que los adultos trabajaran como guías desde las primeras etapas de la vida para que el aprendizaje se desarrollara en libertad.

En el período comprendido desde 1840, cuando se estableció el primer jardín infantil en Blankenburgo, hasta 1851 (cuando se prohibieron en Prusia por considerárseles subversivos y antirreligiosos) los jardines comenzaron a formar parte de las iniciativas de educación y atención a la infancia. Esto se logró gracias a la labor conjunta de personas que compartían con Froebel el compromiso con la educación, además de una base cultural, religiosa y de lenguaje (Bauernschuster y Falck: 2014; 3). Por ejemplo, Langenthal, Schmidt, Ida Seele, el pastor Hildennagen y su cuñada Amalie Kruger, Müller, Luise Frankenberg, Marie Christ y August Kohler participaron en la organización de los primeros centros. Durante esa etapa de difusión local y regional se abrieron jardines 
infantiles en Gera, Rudolstadt, Darmstadt, Quetz y más tarde en Dresde, Erfurt, Gratz, Gotha, Hamburgo, Hildburghausen, Lunen y Marienberg (Michaelis y Moore: 1891; 319). Esta labor colectiva y sostenida señala una tendencia hacia la difusión de la pedagogía del jardín infantil en respuesta a necesidades del contexto social.

Berger explica que el origen de las instituciones de educación y cuidado para niños y niñas se relaciona con las exigencias de la incipiente industrialización, cuando emergió el proletariado y el trabajo infantil y femenino en las industrias y la burguesía buscó el control económico y político. En ese contexto se generó un movimiento de apoyo a los jardines infantiles, al que se unieron integrantes del movimiento revolucionario de 1848-1849 en los estados alemanes y del movimiento de las mujeres. El análisis del Periódico de las Mujeres ("Frauen Zeitung"), editado por la líder feminista Louise Otto, así como el estudio de la biografía de algunas maestras pioneras (Berger: 1995;3) demuestra la interrelación de dichos movimientos (Munchow: 2006; 283). Por otro lado, Baader confirma los planteamientos de Berger y Munchow. Esta autora agrega que la difusión de los jardines infantiles fue tema central de los movimientos liberales y democráticos de ese periodo y también del movimiento magisterial y del movimiento a favor de la educación de las mujeres (2015). Para esta autora en el periodo pre-revolucionario y revolucionario de 1848, los jardines infantiles despertaron gran interés por su apertura a todas las clases sociales y religiones; por esa razón, al movimiento se integraron otros como el emergente movimiento de libre pensamiento y el movimiento sindical. Esto indica que la propuesta de Froebel generó una amplia respuesta y ocupó un lugar de gran importancia en acontecimientos sociales y políticos.

De su impacto y auge da cuenta la apertura de 44 jardines infantiles en Prusia solo en el año 1848.
Debido a la prohibición y al cierre de los jardines infantiles en 1851, el proceso de difusión se proyectó hacia otros países. Cuando se levantó la prohibición, la labor continuó en los estados alemanes con la apertura de jardines infantiles e institutos para la docencia, los que se contaron entre las primeras escuelas profesionales para mujeres (Allen en Wollons: 2000; 26). Dichos institutos fueron impulsados por personas cercanas a Froebel como su sobrino Karl Froebel y su sobrina Henriette Breymann, así como sus alumnas, la Baronesa Marenholtzvon Bulow y Johanna Goldschmidt. En ellos se adoptaron diversos enfoques conforme a ideas políticas y objetivos.

Karl Froebel y Johanna Goldschmidt aspiraban a reducir tensiones sociales, mejorar las condiciones de vida de las familias pobres y contribuir a la educación de las mujeres. Goldschmidt escribió sobre su pensamiento pedagógico y se dedicó a la educación del proletariado (Berger: 1995; 1). Con base en el socialismo utópico y los objetivos mencionados Froebel y Goldschmidt se dedicaron a promover la enseñanza de la pedagogía de Froebel en el Seminario de Hamburgo fundado en 1860; también abogaron por un modelo de familia libre y fundaron jardines infantiles. La acusación de que los jardines infantiles eran subversivos y antirreligiosos se ha asociado a sus ideas radicales (Beatty: 1995; 49).

La Baronesa Berthe von Marenholtz-Bulow, conocida por sus ideas liberales, fue de las principales divulgadoras. Ella fundó la Sociedad para la Educación Popular en Berlín y estableció en Dresde en 1873 una escuela para enseñar la pedagogía y también jardines infantiles de pago y gratuitos que ponían el énfasis en la formación de la ciudadanía, la educación vocacional, el orden y la higiene. Ella consideraba los jardines infantiles como estrategia de control social; por esa razón abogó por la separación según la clase social y para que mujeres educadas de las clases altas se hicieran cargo de esta labor 
filantrópica hasta que las madres de la clase trabajadora tuvieran una mejor educación (1995; 50). También abogó para que el método de Froebel se pusiera en práctica en las guarderías y escribió sobre la misión educativa de las mujeres (Allen: 1986; 142).

Henriette Schrader-Breymann fue líder del movimiento liberal de los jardines infantiles que se desarrolló luego de la prohibición. Ella fundó un jardín infantil y un programa de enseñanza para maestras en Berlín en 1874. La Casa Pestalozzi Froebel- adquirió reputación internacional por la enseñanza de la pedagogía y tuvo alumnas del extranjero. Allen ha observado que "la complejidad teórica de la pedagogía de Froebel le confería estatus profesional a quienes la practicaban"; por tanto, las tareas relativas a su enseñanza y aprendizaje en los institutos mencionados representaban nuevas oportunidades educativas y laborales (Wollons: 2000; 26).

Esta perspectiva histórica permite comprender cómo se fue desarrollando el proceso de difusión de la pedagogía iniciado por Froebel y como adquirió una dimensión social y política en el contexto de la incipiente industrialización y de los movimientos sociales a mediados del siglo XIX. Los antecedentes también revelan que en los esfuerzos de difusión se destacó la participación mayoritaria de las mujeres y se mantuvo el enfoque en la enseñanza y el aprendizaje para la educación preescolar y la docencia. A partir de todas esas actividades, el jardín infantil se fue dando a conocer, encontró apoyo y también censura. A raíz de la prohibición y en consecuencia, del cierre de muchos jardines infantiles, la tendencia a la diseminación se vio limitada, pero se proyectó en otros países.

\section{Difusión internacional de la pedagogía del jardín infantil a mediados del Siglo XIX}

De acuerdo con Wollons (2000), la popularidad del jardín infantil y su amplia diseminación desde el siglo XIX hasta el siglo XX permite apreciar cómo una propuesta pedagógica moderna considerada idónea para el bienestar de la niñez se fue difundiendo y transformando para favorecer el desarrollo infantil e influir en valores de identidad nacional y prácticas familiares.

El jardín infantil fue introducido primero de manera directa con base en el modelo de Froebel, luego a través de quienes fueron sus estudiantes. La modalidad de introducción secundaria fue aplicada por ejemplo por misiones católicas o protestantes que enseñaron esta pedagogía en países de Asia, África y América Latina desde fines del siglo XIX. La introducción terciaria utilizó un modelo más distante del de Froebel; por ejemplo, el modelo japonés usado como base para la implementación del jardín infantil en China $(2005 ; 5)$. Con todas esas experiencias se fue forjando una base teórica y metodológica con variantes según el contexto de aplicación y se fue conformando una percepción favorable en algunos sectores por las ventajas potenciales que representaba para proyectos educativos, sociales o nacionales.

En cuanto al inicio de la difusión internacional, Allen, Brehoney y Wollons señalan la labor de personas que habían aprendido directamente con Froebel y por sus ideas liberales fueron exiliadas a raíz de la revolución de 1848 y de la prohibición de los jardines infantiles. Entre ellas se destacan la Baronesa Bertha Marenholtz-von Büllow y las hermanas Berthe y Margarethe Meyer. Von Büllow gestionó el levantamiento de la prohibición, financió y abrió muchos jardines infantiles a través de la Asociación para la Educación Popular, escribió Reminiscencias de Froebel y viajó por varios países de Europa 
Occidental difundiendo sus ideas. Berthe y su esposo Johannes fundaron en 1851 el primer jardín infantil en Londres, ciudad que por su poderío económico era punto de enlace para movimientos internacionales.

Como agentes de difusión de estas ideas, publicaron manuales para la aplicación del método de Froebel y participaron en congresos pedagógicos y ferias internacionales con exhibiciones de aulas modelo y trabajos realizados por estudiantes. Por ejemplo, con motivo de la Exhibición y Congreso Internacional de 1854 en Londres, Marenholtz expuso material educativo y Berthe Rongue dictó una conferencia. Esos eventos contaban con la participación de visitantes y expositores de muchos países. El jardín infantil recibió elogios como "el método de desarrollo infantil más atractivo, original y filosófico que el mundo había visto" y ganó adeptos como Barnard quien abogó y gestionó su establecimiento en los Estados Unidos (Barnad: 1880; 1).

En ese país Margarethe y su esposo Carl Schurz implantaron en 1855 el primer jardín infantil de habla alemana en el pueblo de Watertown, Wisconsin (Wollons: 2000; 62). Esta pareja formó parte de un grupo que divulgó el jardín infantil a través de literatura sobre temas pedagógicos y a través de la fundación deacademias. En esas instituciones participaron personas consideradas de ideas radicales como Adolph Douai quien llevó la idea del jardín infantil a Nueva Jersey.

Se sabe de iniciativas individuales llevadas a cabo por personas que viajaron a Europa y que al regresar a su lugar de origen pusieron en práctica el jardín infantil. Un ejemplo de ello es el primer jardín infantil brasileño fundado por Emilia Erichsen en 1862 en Castro, Paraná.

El énfasis en la enseñanza para la docencia contribuyó a la labor de diseminación pues se llegó a contar con personas preparadas para poner en funcionamiento jardines infantiles y formar al magisterio. En 1871 Enrique Laubscher, que había sido alumno de Froebel, llegó a México donde desarrolló una amplia labor en escuelas públicas y privadas de varios estados del país (Campos: s/f; 2). Laubscher es reconocido como fundador del primer jardín infantil y como maestro en la Escuela Primaria Modelo (fundada en 1883) y en la Escuela Normal (fundada en 1885) en Orizaba, instituciones clave en la reforma de la educación mexicana (Zea: 1963; 530).

En la aplicación y enseñanza influyeron las ideas religiosas y políticas; por ejemplo, Elizabeth Palmer Peabody, una de las principales divulgadoras del jardín infantil en Estados Unidos, lo concebía como ministerio evangelizador, espacio de contacto con la espiritualidad encarnada en la niñez y antídoto contra el materialismo. Ella veía en el trabajo educativo una vocación basada en cualidades maternales, no biológicas sino espirituales y una respuesta alllamado de Dios a trabajar por la niñez. Con esa perspectiva, Peabody reclutó maestras en Alemania y junto a su hermana Mary fundó el primer jardín infantil de habla inglesa en Boston y publicó El Mensajero del Jardín Infantil, boletín de la Sociedad Froebeliana (Peabody: 1877; 192). Las hermanas Peabody intercambiaron ideas con la escritora y educadora argentina Juana Paula Manso, fundadora del primer jardín infantil público en Buenos Aires. Esta colaboradora de Sarmiento dirigió los Anales de la Educación Común, revista dedicada a la docencia y "a la difusión de los avances de la educación moderna y democrática, como por ejemplo las ideas de Pestalozzi y Froebel" (Puiggrós: 2003; 55). Mary, junto a su esposo, Horace Mann, reformador de la educación estadounidense, colaboraron con Sarmiento en el reclutamiento de docentes para la fundación de escuelas normales, donde se abrieron jardines infantiles y se continúo la difusión de dicha pedagogía. Estos ejemplos forman parte de numerosas acciones desarrolladas en diferentes países en las que se observa que la difusión e implementación fueron procesos interrelacionados. Ambos 
procesos contribuyeron a la proyección internacional del jardín infantil. La difusión contribuyó a la implementación y ésta fue también una forma de divulgación apoyada por diversas estrategias.

Las traducciones de la obra de Froebel y de escritos acerca de su pedagogía también favorecieron la continuidad de la tendencia a la divulgación internacional. A través de la publicación en 1871 de La Cultura en el Jardín de Infantes, Wiebe abogó por la causa del kindergarten con la intención de extender a futuras generaciones los beneficios derivados de una institución "eminentemente dedicada a educar ciudadanos libres en un país libre" $(1871 ; 9)$. Este educador consideraba que uno de los grandes logros de Froebel consistió en la elaboración y aplicación de material educativo con el fin de preparar niños y niñas para todas las situaciones de su vida futura y las variadas ocupaciones que tuvieran que desempeñar. En opinión de Peabody, el libro de Wiebe fue el documento más importante puesto a disposición del pueblo norteamericano para la diseminación de las ideas de Froebel (1877; 192). En México el maestro Manuel Guille en 1873 tradujo la obra Método Intuitivo que trataba sobre los métodos de Pestalozzi y Froebel (Campos: s/f; 2). En 1885 José Abelardo Núñez tradujo al español La Educación del Hombre dando a conocer una de las principales obras de Froebel. En su labor como organizador de las escuelas normales de Chile, Núñez visitó los Seminarios de Froebel en Sajonia y Prusia, donde se preparaban institutrices para las escuelas infantiles y expreso su admiración por la calidad de la enseñanza que en ellos se impartía (1883; 38). En Argentina Sarah Chamberlain Eccleston tradujo El Niño y su Naturaleza (1896) de Marenholtz-Bulow, fundó jardines infantiles en Argentina y Uruguay y se dedicó a la enseñanza para la docencia (Peralta: 2009; 33).

En España, la casa editorial Bastinos de Barcelona confeccionaba material educativo como los dones de Froebel y se dedicaba a la edición y exportación de obras pedagógicas a los países de habla hispana. Este tipo de industria también contribuyó a la difusión como lo demuestran los catálogos que según las investigaciones de Ruiz Funes ya circulaban en 1881 (2012: 268).

Agustín Gómez Carrillo en su Instrucción Pedagógica Centro-americana (1883) explicó algunos elementos teóricos y metodológicos del sistema de Froebel y comentó acerca de su posible generalización para mejora de la enseñanza. También reportó que el jardín infantil se iba "abriendo paso de un modo eficaz en la América Central", según se podía apreciar en planteles organizados para niños y niñas en Guatemala (1883; 121). En el Primer Congreso Pedagógico Centroamericano efectuado en dicha ciudad en 1893, las delegaciones discutieron entre otros puntos la educación de las mujeres centroamericanas, la importancia del jardín infantil y debatieron si era conveniente adaptarlo al contexto regional, a la aplicación en la enseñanza parvularia y a la enseñanza de la población infantil indígena.

Desde Nueva York en 1890, José Martí se pronunció a favor de la educación de los pueblos para que aprendieran a defenderse y vivir con honor. Con el fin de que el ser humano conociera lo bueno y lo bello desde la infancia, abogó para que la ciudad toda fuera una escuela y hubiera un jardín infantil en cada calle (1902: 93).

Con base en lo expuesto, se puede afirmar que a fines del siglo XIX la pedagogía del jardín infantil había llamado la atención de personas que asociaban su potencial con posibles reformas educativas y sociales y con la calidad educativa, la libertad, la democracia, la espiritualidad y otros valores morales.

Como resultado de los esfuerzos iniciales de difusión en Estados Unidos, entre 1870 y 1880 se comenzaron a formar maestras de kindergarten en algunas escuelas normales, 
se fundaron jardines infantiles privados y de beneficencia y en la ciudad de San Luis se integraron al sistema de educación pública. De esa manera, se abrieron nuevos espacios y se crearon modelos de aplicación según las necesidades de la población, la situación social y educativa del país y las expectativas sobre la educación de acuerdo con ideas políticas, valores, clase y religión. Por ejemplo, los jardines infantiles de beneficencia se dedicaban especialmente a la población de bajos recursos y eran financiados por asociaciones religiosas $\mathrm{o}$ filantrópicas. La Imagen No. 1 representa El jardín infantil de la Casa Industrial de
Boston, 1881, donde además de la educación preescolar, se impartían clases para madres y padres de familia y se organizaban visitas a los hogares. Este centro formaba parte de los 31 jardines infantiles que llegaron a funcionar en esa zona con fondos proporcionados por Pauline Agassiz y con la ayuda del sistema escolar que suministraba los locales. En ellos se atendía a la población infantil muy pobre que quedaba sin atención cuando los padres y madres, muchos de ellos inmigrantes, salían del hogar a trabajar. También desde estos centros se apoyaron iniciativas de enseñanza para la docencia y de investigación en el campo de la psicología (Beatty: 1995; 75).

Figura No. 1. El Jardín Infantil de la Casa Industrial Boston, $1881 .^{1}$

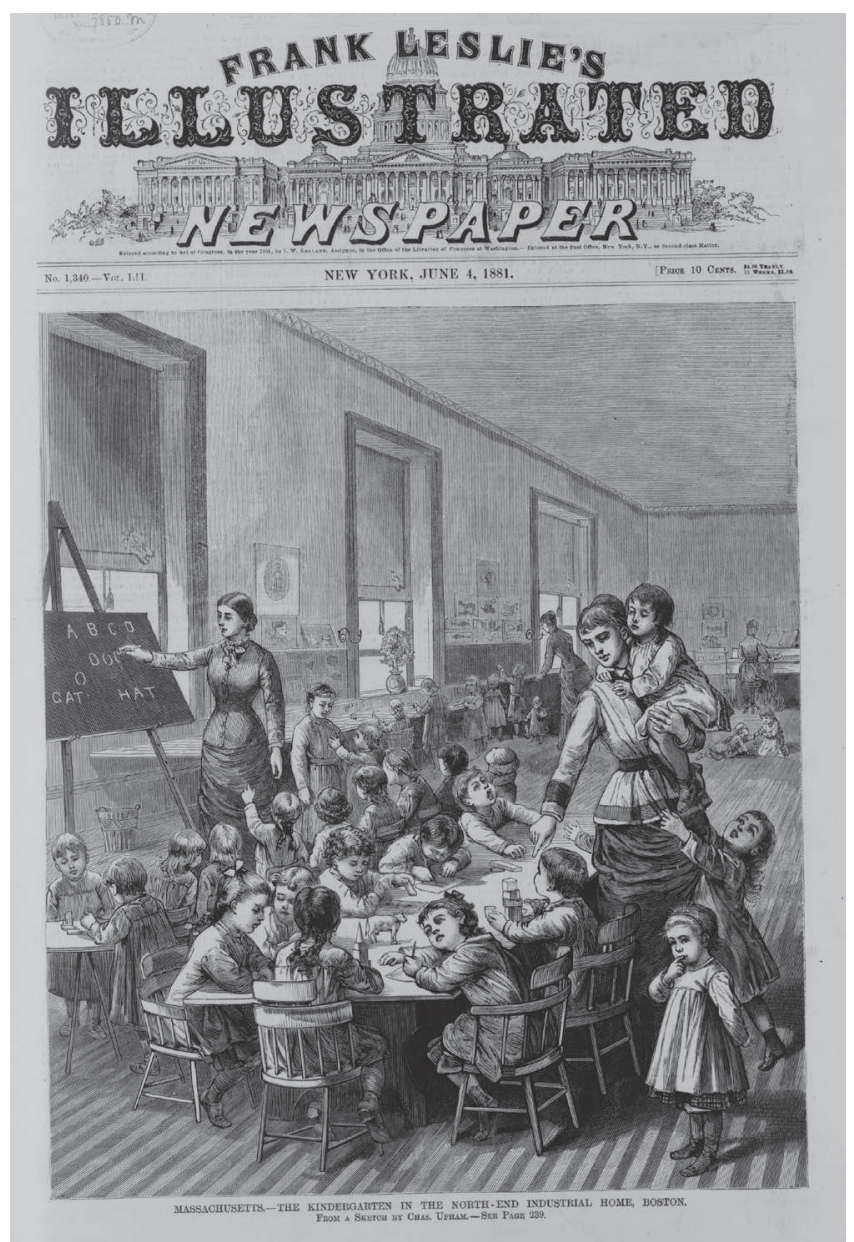

1 Fuente: El Diario de Frank Leslie. No. 1340. Vol. LII. Nueva York. 
En esta imagen se aprecia un grupo de niños y niñas de edad preescolar, algunos están de pie, otros sentados en pequeñas sillas ubicadas alrededor de las mesas, otros se encuentran sentados en el suelo. Se observa que están participando de diversas actividades individuales o colectivas, tales como conversaciones, juegos y trabajos manuales. El salón cuenta con mobiliario para cada uno de los niños y niñas y con recursos didácticos como los dones de Froebel y láminas de animales en las paredes. La escena del salón con amplias ventanas, flores y un piano representa un espacio educativo agradable a cargo de un grupo de cuatro mujeres. Cada una de ellas está cerca de un grupo de niños y niñas mientras realiza una actividad como tocar el piano o escribir en la pizarra. Por la información de un inspector escolar se comprende que asistían niños y niñas provenientes de familias pobres, entre ellas inmigrantes de Polonia, Italia, Rusia y Bohemia. Su descripción del jardín infantil hace referencia a un segundo hogar pleno de actividad y alegría, donde se ofrecía educación, alimento y atención a la higiene personal. Experiencias como ésta fueron valoradas por la enseñanza y la atención que brindaban, pero también -como en el caso de este inspector- fueron percibidas como estrategia preventiva contra problemas que podían derivarse de la anarquía, el socialismo y el sindicalismo (Beatty: 1995; 74). En síntesis, la experiencia del jardín infantil de Boston que retrata la imagen ofrece una aproximación a la manera en que se puso en práctica la pedagogía de Froebel para la educación preescolar y la atención de niños y niñas en un contexto urbano de pobreza. El programa integró por una parte, elementos propuestos por Froebel como el juego, la actividad, los dones, la participación de las mujeres como maestras y por otra parte, el enfoque asistencial de cuidado, salud, nutrición y la intervención familiar. El financiamiento provenía de contribuciones de una familia influyente y adinerada y apoyada por el sistema escolar para beneficio de la población infantil de bajos recursos. Este jardín infantil representa una de las múltiples experiencias de implementación llevadas a cabo a fines del siglo XIX que tomaron como referencia el modelo de Froebel, lo adaptaron a sus necesidades y lo dieron a conocer.

En la década anterior al establecimiento del jardín infantil de Granada, existía en Estados Unidos acceso a material educativo y literatura especializada, personal capacitada y experiencia para implementar el jardín infantil y enseñar la teoría y el método. Las principales ciudades del país contaban con jardines infantiles y también se dedicaban a la educación para el magisterio. Por otro lado, el jardín infantil gozaba de prestigio en las clases medias y altas como una obra filantrópica y una profesión idónea para las mujeres. También contaba con el respaldo de docentes, intelectuales y oficiales en la educación que valorando los resultados obtenidos y su potencial abogaban por su causa (Beatty: 1995; 61).

Como ya se ha mencionado, muchos otros países también disponían de experiencia en la aplicación de la pedagogía, en el desarrollo de actividades culturales, editoriales y comerciales que contribuyeron a la circulación de las ideas y de recursos didácticos. Las personas que tenían los recursos para viajar de Nicaragua al extranjero pudieron tener acceso a ellas y la posibilidad de introducirlas al país. Lo anterior sintetiza algunos antecedentes a tener en cuenta para comprender la forma en que la pedagogía del jardín infantil se introdujo por primera vez en Nicaragua en el contexto de la tendencia hacia la difusión e implementación internacional.

\section{Introducción de la pedagogía del jardín infantil en Nicaragua}

En su apreciación sobre los comienzos de la educación inicial en Nicaragua, Peralta observa la confluencia de un conjunto de circunstancias, factores y situaciones del país 
y la actuación de personas que reconocieron la importancia de la educación inicial cuando el país estaba fortaleciendo sus instituciones básicas y estableciendo sus primeras líneas de desarrollo (Peralta: 2009; 37). Como ya se ha señalado, es necesario agregar el contexto de difusión e implementación internacional porque, como se verá más adelante, fueron maestras provenientes de Estados Unidos quienes pusieron en práctica el jardín infantil en Granada. También es necesario considerar el contexto histórico regional y nacional. Ossenbach afirma que a finales del siglo XIX se estaba consolidando en América Latina el estado oligárquico, que sostenía como objetivos el orden y el progreso. Con el fin de desarrollar los sistemas de instrucción pública nacionales, el estado asumió la función de la educación e impulsó la enseñanza laica en muchos países (1993; s/p). En Nicaragua la organización y el financiamiento de la educación primaria había estado en manos de los padres de familia y de los municipios hasta 1877 cuando ésta se declaró gratuita y obligatoria (Wolfe: 2007; 74). Por tanto, esta es una etapa de conformación del sistema educativo y de fundación de instituciones educativas. los ideales de progreso y que instituciones como la biblioteca eran esenciales para educar a la ciudadanía (1992; 302).

De acuerdo con sus Estatutos, el Colegio de Señoritas fue creado como plantel de enseñanza para niñas "de conformidad con la escritura de compromiso celebrada entre el Supremo Gobierno y una Junta de Padres de Familia." (Gobierno de Nicaragua: 1882; Capítulo 1, Artículo 1). Sobre su trascendencia, Arellano señala que el Colegio llegaría a ser "el alma mater de la enseñanza normal, femenina y moderna del país" (1999; 88). Toledo de Aguerri afirma que "las seis primeras alumnas graduadas en la $2^{\text {a }}$. Enseñanza en el "Colegio de Señoritas de Granada" y difundidoras con otras de los modernos métodos pedagógicos" fueron Juana Vicenta Cabrera, Isabel Espinoza Carranza, María Medina v. de Rodríguez, Zoila Mora de Dessurreault, Francisca Berta Rivas y Josefa Toledo de Aguerri (1920; 276). La Figura No. 2 presenta un grupo de estudiantes del Colegio en 1884 y puede ser que en ese retrato se encuentren algunas de las alumnas mencionadas. Sin embargo, no se dispone de datos para identificarlas.

Peralta sostiene que el primer jardín infantil nicaragüense fue establecido como parte del plan del Colegio de Señoritas en la Figura No. 2. Grupo de Alumnas del Colegio de Señoritas de Granada, $1884 .{ }^{2}$ ciudad de Granada durante la presidencia de Joaquín Zavala (1879-1883) (2009; 37). Esta administración forma parte del período de la República Conservadora de los Treinta Años, cuando el gobierno impulsó importantes iniciativas culturales; por ejemplo, la fundación de la Biblioteca Nacional. Coloma señala que entonces se creía que la Ilustración daría impulso a

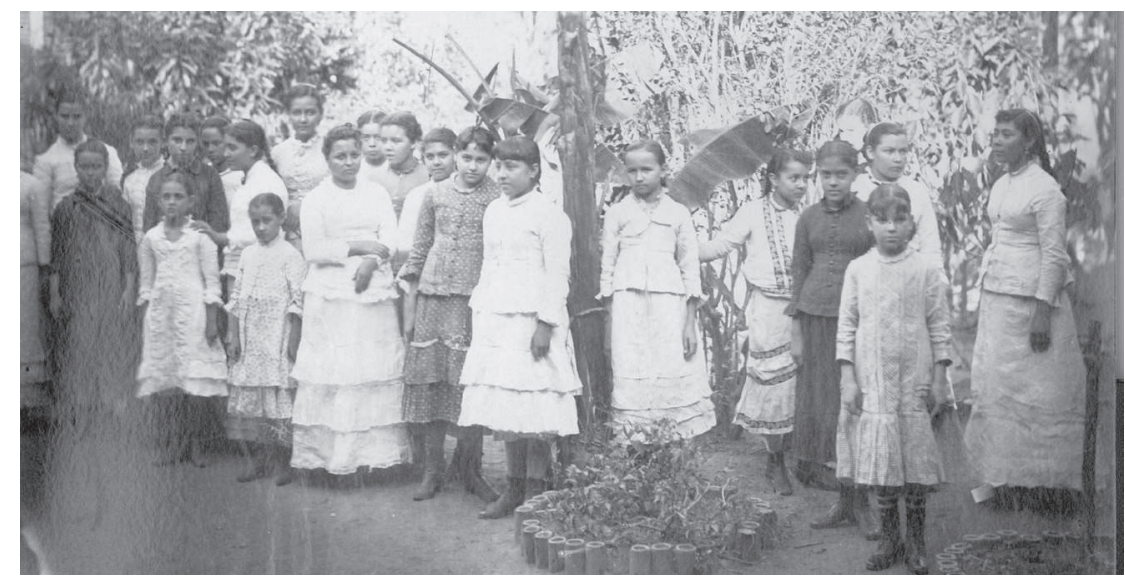

2 Fuente: Cortesía del Archivo Nacional de Estados Unidos, Fotografía no. 401-XPN-3D5. Procedencia: Archivo Familiar Robert E. Peary. Agradezco a Holly Reed por facilitar esta imagen y autorizar su publicación. 
Con respecto al jardín infantil, desde la incepción del Colegio de Señoritas de Granada, éste se incluyó en el programa de enseñanza elemental como curso de la primera sección con la denominación de kindergarten:

“Capítulo 3. Enseñanza

Art. $9^{\circ}$.

$1^{\text {a }}$. Escuela elemental

$2^{\mathrm{a}}$. Intermediaria ó fundamental

$3^{\text {a }}$. Complementaria.

Art. 10: La enseñanza de la primera sección se arreglará en tres cursos. En el primero se hará uso exclusivo del sistema objetivo (kindergarten); en el segundo habrá combinación del sistema subjetivo y objetivo y de la misma en el tercero, en grado superior" (Gobierno de Nicaragua: 1882; Capítulo 1, Artículo 1).

Los relatos de Cuadra Pasos confirman la puesta en práctica del jardín infantil. Dicho autor fue uno de los primeros alumnos y dejó constancia de esa experiencia:

“El año de 1882 trajeron los padres de familia de Granada un grupo de profesoras alemanas y norteamericanas, para la dirección y profesorado del Colegio deSeñoritas. Tenía yotres años de edad y recuerdo estas novedades porque afectaron la formación de mi inteligencia y de mi carácter en la infancia... Una de las innovaciones implantadas en tal año por el profesorado extranjero fue el Kindergarten, sistema creado por el alemán Federico Froebel, que inicia a los niños en los primeros conocimientos de las letras, de la naturaleza y de las relaciones sociales, divirtiéndolos al mismo tiempo con juegos adecuados para tener alegres sus espíritus, en contradicción con el viejo sistema de los castigos que expresaba la cruel sentencia de que las letras con sangre entran" (1966; 114)).

Lo anterior constituye evidencia del año y lugar de fundación del jardín infantil, de su funcionamiento, de la presencia de maestras provenientes del extranjero y de la aplicación del método de enseñanza de Froebel en Nicaragua durante la misma época de difusión e implementación en otros países. Además de expresar la trascendencia que tuvo en su formación personal, Cuadra Pasos contrasta el viejo sistema de castigos con el nuevo que se aplicaba en su jardín infantil, basado en Froebel, quien proponía el valor educativo del juego, la naturaleza como fuente de enseñanza y la armonía y la cooperación en las relaciones.

Una dimensión importante del jardín infantil fue su articulación con la enseñanza para la docencia, como también lo fue en la propuesta de Froebel y en su aplicación en los ejemplos antes mencionados.

Peralta sostiene que el jardín infantil funcionó dentro del Colegio de Señoritas como un "centro de aplicación de esta Escuela Normal" y que desarrolló "la primera formación de maestras con esa especialidad". (2009; 41). Así las alumnas estuvieron en contacto con el primer jardín infantil y continuaron la labor de enseñanza para maestras de jardines infantiles. Por lo tanto, existe una relación entre el Colegio de Señoritas y el jardín infantil en cuanto a su fundación, funcionamiento y enfoque en la enseñanza de las mujeres para la docencia. También existe continuidad entre dicha experiencia y otras en el ámbito internacional a las que se ha hecho referencia porque mantuvieron a la vez el enfoque en la educación infantil y la enseñanza para la docencia.

El análisis documental revela que desde 1880 se había comenzado a desarrollar un conjunto de tareas organizativas, de gestión y divulgación para implantar un colegio de niñas, por iniciativa de Roberto Lacayo. A 
través de su correspondencia se conoce esa etapa de planeamiento.

Lacayo había expresado en una carta dirigida a los padres de familia de Granada la necesidad e importancia de llevar adelante este proyecto. Asimismo, había manifestado la posibilidad de que el gobierno de Nicaragua sufragara gastos de instalación y facilitara el local de acuerdo a un presupuesto ya elaborado. Esto sugiere que ya se había trazado un plan y se habían sostenido conversaciones con el gobierno (Lacayo: $1881 ; 1){ }^{3}$

Un año antes, Lacayo como Prefecto de Granada había abogado ante los padres de familia por la fundación del Colegio de Señoritas y en favor de la organización de una sociedad anónima para su administración y financiamiento por medio de acciones. En esa ocasión solicitó que se publicara un artículo en El Porvenir para dar a conocer las ventajas que dicha institución traería al país a favor de la educación de las mujeres (Lacayo: 1880; 1). Tal como indicó en su carta a los padres de familia, Figura No. 3, el objetivo principal de esas gestiones consistía en poner a disposición de la sociedad una institución a la altura de los establecimientos europeos "en el que nuestras hijas se eduquen e instruyan convenientemente cual corresponde a los mejores y más adelantados sistemas educativos, a la muy importante misión de la mujer y al papel que debe representar". Para lograrlo se estimaba necesaria la contratación de docentes en el extranjero como una manera de garantizar una educación de calidad (Lacayo: 1881; 1).

Es necesario tener en cuenta las limitadas oportunidades educativas para la mayoría de la población que era pobre y analfabeta, el estado general poco satisfactorio de los establecimientos de enseñanza, carentes de comodidad e higiene "que algo enseñan pero les falta mucho", según el Reporte de Instrucción Pública (Medina: 1883; 152). En el caso de las mujeres, de acuerdo con el análisis de Rodríguez Rosales, su educación en la primera mitad del siglo XIX se restringía al aprendizaje de la lecto-escritura, aritmética y religión y existía una preferencia entre la clase oligárquica de contratar maestras para la enseñanza privada de las primeras letras en el hogar o la fundación de escuelas privadas, como las de Granada y León (2006; 100). Dicha autora ha llamado la atención al hecho de que las mujeres no contaban con derechos civiles y políticos y su educación se enfocaba en modelar su identidad doméstica; es decir, se enfocaba en labores manuales $u$ otros conocimientos que se consideraban necesarios para el desempeño del papel asignado a ellas como madres y esposas.

Figura No. 3. Fragmento de Carta de Roberto Lacayo a los Padres de Familia de Granada, $1881^{4}$

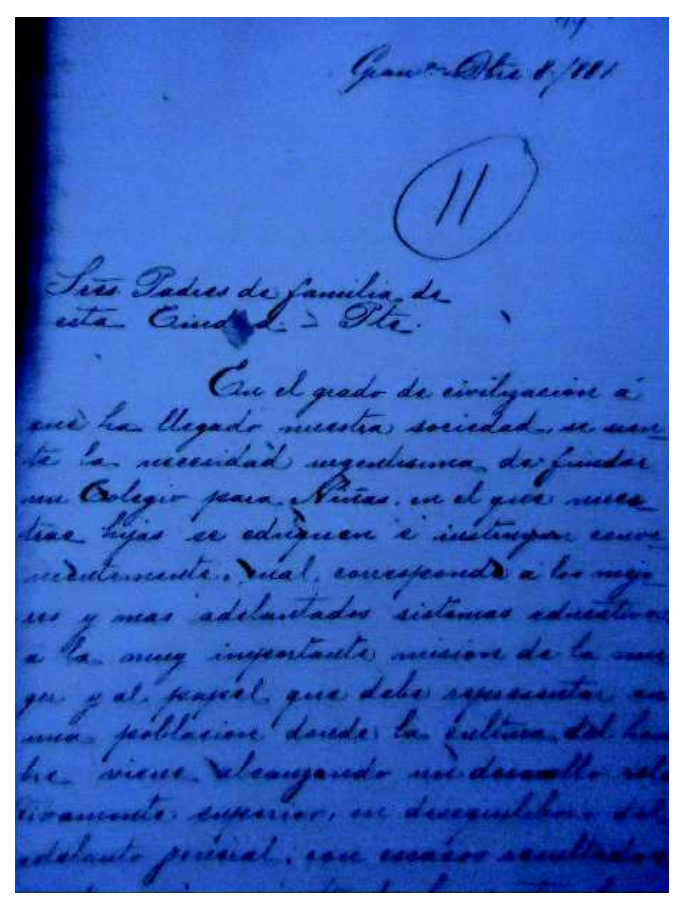

3 Archivo Municipal de Granada. Agradezco a Juanita Blanco Mendoza, Ana Rosa Morales, Eleazar Morales Marenco por su ayuda en la consulta del Archivo.

4 Fuente: Archivo Municipal de Granada, Nicaragua. Solicitudes y diligencias varias, Legajo No. 459, Folio 250. 49-11. 
Lo anterior coincide con el argumento que Lacayo expresaba para obtener apoyo de las familias en favor de la apertura del Colegio:

En el grado de civilización a que ha llegado nuestra sociedad, se siente la necesidad urgentísima de fundar un Colegio para Niñas en el que nuestras hijas se eduquen e instruyan convenientemente cual corresponde a los mejores y más adelantados sistemas educativos, a la muy importante misión de la mujer y al papel que debe representar en una población donde la cultura del hombre viene alcanzando un desarrollo relativamente superior, en desequilibrio del adelanto general, con escasos resultados en el mejoramiento de las costumbres públicas y en desprestigio de un ser que tantos títulos está llamado a ejercer su acción tan poderosa e influencias $\tan$ bienhechoras, en los destinos y en la felicidad humana. La mujer educada, -todos lo reconocemos-, es la esperanza de una sociedad, el verdadero adorno, la dicha y el honor de las familias: así, todos los esfuerzos que hagamos para educarla y engrandecerla será obra civilizadora que reclaman de consuno nuestros intereses más caros en el hogar doméstico (Lacayo: 1881; 1).

Esta carta presenta evidencia de los pasos que la Junta de Padres estaba dando para la fundación del Colegio y de los puntos de vista sobre la necesidad e importancia de la educación para el bienestar de la familia y la sociedad. La carta no menciona la formación en el magisterio ni el jardín infantil como uno de los objetivos, pero muestra con claridad la intención de incorporar avanzados sistemas educativos a la educación de las mujeres por múltiples beneficios especialmente de índole moral. Asimismo, este documento hace referencia al carácter privado de la institución que se proyectaba y al financiamiento por medio de la participación de accionistas en una sociedad.
Con esa visión, representantes del gobierno, como el Ministro Adán Cárdenas, gestionaron en Estados Unidos la contratación de docentes para el Colegio de Señoritas. Entonces ya existían antecedentes de este tipo de gestión pues en años anteriores se había contratado fuera de Nicaragua a profesores para la enseñanza en otras instituciones educativas del país. Un ejemplo fue la contratación de profesores españoles para el Colegio de Granada fundado en 1874 (Barberena Pérez: 1974; 11). Años más tarde, el Doctor Antonio Zambrana afirmó haber estado a cargo de una comisión del gobierno de Nicaragua en Estados Unidos con ese mismo propósito $(1883 ; 3)$.

Lo expuesto hasta aquí sobre el contexto educativo y las gestiones realizadas permite apreciar algunos factores y circunstancias relativas al establecimiento del Colegio de Señoritas y del jardín infantil como parte de dicha institución. Resultado de los esfuerzos dentro y fuera de Nicaragua por la Junta de Padres de Familia de Granada con apoyo del Gobierno, llegaron a Nicaragua las maestras procedentes de Estados Unidos. El periodista Enrique Guzmán registró este acontecimiento en su Diario Intimo con fecha 18 de octubre, 1882. Poco tiempo después también anotó el $1^{\circ}$ de diciembre del mismo año, fecha de inauguración del Colegio de Señoritas.

Al año siguiente ya estaba funcionando el jardín infantil a cargo de una de las recién llegadas maestras, según manifiesta Cuadra Pasos:

En el mes de mayo de 1883 me inscribió mi madre como alumno del Kindergarten. Era su directora una señorita americana llamada Miss Moore ¡Era bella mi maestra! y desde el primer día me cautivó: esbelta, con unas mejillas siempre sonrosadas, dos ojos celestes, que junto con su sonrisa, le servían para dominar a sus discípulos, agradándolos aún cuando contrariara sus ímpetus 
desordenados... Ella nos organizó en mesas cuadradas, en que nos sentábamos tres a cada lado; dos lados de varones y dos de mujeres. Fueron mis compañeros de mesa, todos ya desaparecidos, Joaquín Pasos, Carlos Gómez, Carlos Ferrey, Rafael Vela y Juan Zavala. En la punta de mi lado estaba mi asiento, y era mi vecina inmediata una niña, bonita, juguetona y traviesa, que se llamaba Zulema (1966; 114).

Por este relato se cuenta con una descripción de la señorita Moore, quien fue la maestra a cargo del jardín infantil, y se dispone de una referencia a la organización del aula y a la admisión de niñas y niños. También se dispone de los nombres de cinco alumnos y de una alumna, parte del primer grupo en el recién fundado "kindergarten" establecido especialmente para la niñez en edad preescolar, conforme a la propuesta de Froebel de brindar educación acorde a las etapas de desarrollo. Los datos que ofrece la biografía de Toledo de Aguerri coinciden con los proporcionados por Cuadra Pasos con respecto al año de establecimiento del jardín infantil y el grupo docente especializado. Esta educadora pionera de la educación inicial en Nicaragua sostiene que "el kindergarten se estableció en Nicaragua en 1883 (casi al mismo tiempo que en otros países más adelantados que el nuestro) en el Colegio de Señoritas de Granada de gratísima recordación, fundado por esa misma época. Bien establecido con profesorado especial y espléndido material de enseñanza, deficiente sólo en relación al local apropiado... que carecía de jardines y por lo tanto, de los niños con la naturaleza" (López: 1988; 168). Su valoración positiva de la calidad de ese centro de enseñanza parten de una experiencia de vida como estudiante de magisterio y como una de las primeras graduadas del Colegio de Señoritas y años más tarde como destacada maestra de dicha institución y de muchas otras instituciones dedicadas a la educación inicial y a la enseñanza para el magisterio en el país. Al hacer referencia a los jardines y la relación de niños y niñas con la naturaleza, Toledo de Aguerri resalta uno de los elementos fundamentales de la propuesta de Froebel. El nombre jardín infantil era una metáfora inspirada en el pensamiento romántico, pero también un espacio destinado para el cultivo de parcelas para que al aire libre niños y niñas se conocieran a sí mismos, estuvieran en contacto con la naturaleza y en unidad con Dios. Desde esa perspectiva, se comprende que para Toledo de Aguerri resultara notable su ausencia en el jardín infantil de Granada. Por otra parte, al señalar que este se fundó "al mismo tiempo que en otros países más adelantados que el nuestro", Toledo de Aguerri sostiene la coincidencia temporal con respecto al proceso de difusión de los jardines infantiles a nivel internacional.

De los "felices resultados de ese plantel de enseñanza" da cuenta una crónica del Diario de Nicaragua (10 de marzo de 1883), que elogió el desempeño de las alumnas y maestras del Colegio de Señoritas en los exámenes públicos efectuados al concluir el primer año. Los niños y niñas de 3 a 5 años y la maestra del jardín infantil, participaron con éxito en esos exámenes ya que demostraron disciplina y conocimientos de dibujo, lectura, de palabras en inglés, de los números, de suma, del pentagrama, los colores, las partes del cuerpo humano y de los animales. La crónica menciona algunos recursos didácticos utilizados, tales como pizarra, papel, láminas, los dones de Froebel (cubo, bola, cilindro) y su importancia para el desarrollo (Toledo de Aguerri: 1920; 271).

Además de informar que el plan de enseñanza establecido en los Estatutos se llevó a la práctica de manera satisfactoria en todos los niveles, El Diario da a conocer algunas actividades que los niños y las niñas llevaban a cabo en el jardín infantil. Esos datos también confirman la aplicación de la pedagogía del jardín infantil en dicha institución. Toledo de Aguerri destaca que en la dirección y enseñanza, el grupo de docentes transmitió ideas e introdujo prácticas de acuerdo a la 
pedagogía de Pestalozzi (educador con quien Froebel aprendió y colaboró) y de Froebel, hasta entonces desconocidas en Nicaragua $(1920 ; 275)$.

El carácter privado y urbano restringió el acceso a la población que disponía de recursos para pagar la matrícula o las relaciones para obtener una beca. Por lo tanto, el interés de Froebel de que la pedagogía del jardín infantil llegara a todas las clases sociales no se hizo realidad en esas circunstancias en el jardín infantil del Colegio de Señoritas.

En síntesis, el punto de vista de Cuadra Pasos desde su propia vivencia como alumno y de Toledo de Aguerri como estudiante y maestra confirman la aplicación de la pedagogía del jardín infantil en el Colegio de Señoritas a fines del siglo XIX. En este periodo otros grupos docentes se dedicaban a la difusión internacional, de acuerdo con los estudios de casos realizados por Wollons (2000). Por lo tanto, la experiencia del jardín infantil de Granada no es aislada, sino que forma parte de una tendencia a la difusión e implementación en el contexto internacional. Lo anterior demuestra que la pedagogía del jardín infantil se introdujo en Granada por mediación de las maestras de Estados Unidos quienes se nutrieron de la experiencia acumulada en el sostenido proceso de divulgación y aplicación internacional. Mary E. Oliver, Emily C. Day, Sara Felton, Mary Robinson, P. E. Deuhurst y Mr. Ottis formaron parte del grupo de profesoras que llegaron a Granada desde Estados Unidos, de acuerdo con Peralta $(2009 ; 41)$. De ellas se sabe que profesaban una religión protestante y que habían realizado estudios universitarios o de magisterio. Por ejemplo, Emily C. Day se graduó de la Escuela Normal del Colegio Hunter de Nueva York.

Figura No. 4. Grupo de Profesoras del Colegio de Señoritas, $1884^{5}$.

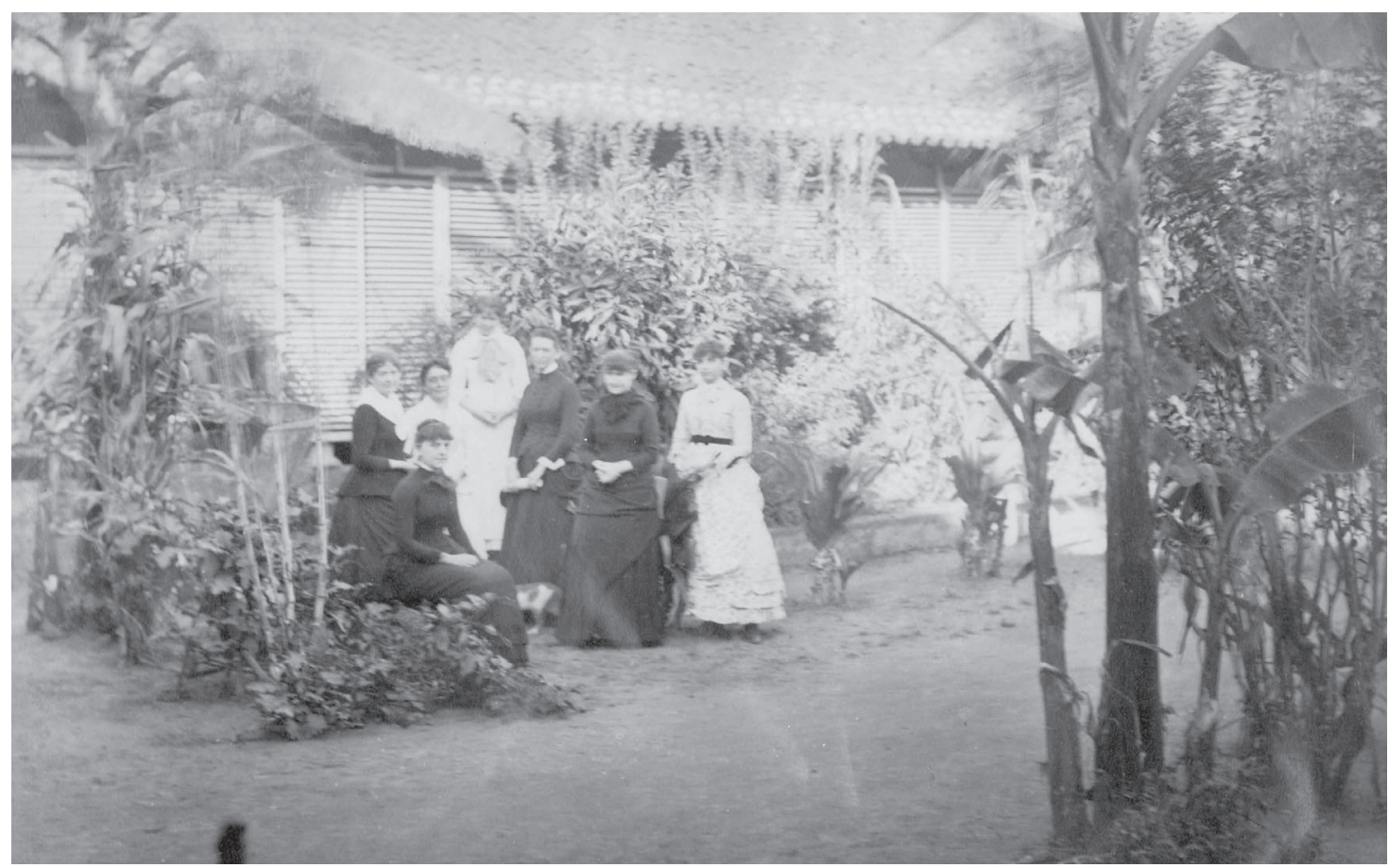

5 Fuente: Cortesía del Archivo Nacional de Estados Unidos, Foto no. 401-XPN-3D8. Procedencia: Archivo Familiar Robert E. Peary. Agradezco a Holly Reed por facilitar esta imagen y autorizar su publicación. 
En la Figura No. 4 se aprecia un grupo de siete de las maestras que enseñaron en dicha institución a estudiantes nicaragüenses. Considerando que el registro de la foto no indica el nombre de las maestras de Estados Unidos, no se cuenta con suficiente información para identificar a la maestra del jardín infantil y sus colegas. Sin embargo, el reporte de García Menocal (1886), las identifica como un grupo de docentes del Colegio de Señoritas.

Las investigaciones de López Miranda, Peralta y los escritos de Toledo de Aguerri, además del análisis de fuentes documentales confirman la introducción y puesta en práctica de la pedagogía del jardín infantil en el Colegio de Señoritas de Granada. Esta se llevó a cabo por medio de la labor docente de las maestras de Estados Unidos y también por la participación de la Junta de Padres de Familia que buscaba incorporar los métodos europeos avanzados. El relato de Cuadra Pasos ofrece una perspectiva valiosa porque refiere la experiencia directa de un alumno de un jardín infantil en el siglo XIX. Asimismo, la biografía de Toledo de Aguerri proporciona información de una fuente autorizada por su experiencia directa en el Colegio de Señoritas y su trayectoria destacada como educadora en Nicaragua.

\section{Conclusión}

El contexto de procesos interrelacionados de difusión e implementación de la pedagogía del jardín infantil a nivel internacional contribuyó a su introducción y puesta en práctica en el Colegio de Señoritas de Granada. Desde mediados del siglo XIX, se desarrollaronestrategias y recursos didácticos y se mantuvo el enfoque en la enseñanza y el aprendizaje para la educación infantil y la docencia especialmente de las mujeres, siguiendo el proceso iniciado por Froebel con sus estudiantes y colaboradores. Sin esa labor sostenida de difusión no habría sido posible que la pedagogía del jardín infantil llegara a formar parte del plan de enseñanza del Colegio de Señoritas. Entre las estrategias de difusión se pusieron en circulación las obras de Froebel traducidas a diversos idiomas, se abrieron jardines infantiles y centros de enseñanza para la docencia. También se elaboró y comercializó material educativo y se publicaron numerosos escritos acerca de las ventajas de esta propuesta pedagógica para impulsar reformas.

En Estados Unidos el movimiento de difusión propició el aprendizaje y la implementación de la pedagogía del jardín infantil en instituciones públicas y privadas; por lo tanto, en ese país se contó con personal capacitado para participar en iniciativas de carácter internacional, tales como el Colegio de Señoritas de Granada. Existe evidencia de que en dicha institución, niños y niñas de 3 a 5 años de edad iniciaron su experiencia de aprendizaje conforme a la pedagogía propuesta por Froebel. De igual manera, un grupo de alumnas del país estudiaron esa pedagogía $y$, una vez graduadas, continuaron en el país la labor de difusión e implementación.

Existió una coincidencia en los objetivos del Colegio de Señoritas y los del jardín infantil propuesto por Froebel ya que éste consideraba necesaria la educación de las mujeres para la docencia, para mantener el vínculo entre ellas y los niños y niñas y así impulsar una reforma en la familia y la sociedad. Por su parte, la Junta de Padres de Familia consideraba necesaria la educación de las mujeres para que ellas desempeñaran su papel en el ámbito doméstico y así avanzar una obra de progreso y bienestar de la familia y la sociedad. De esa manera, se observa una relación estrecha entre la educación de la niñez y la educación de las mujeres en los antecedentes de la educación inicial.

Es necesario continuar investigando más allá del proceso de introducción de la pedagogía del jardín infantil hasta tener una visión de la ruta que esta modalidad siguió durante 
el siglo XX en escuelas públicas y privadas del país. Asimismo, es importante seguir el estudio de los antecedentes más allá de las regiones donde tradicionalmente se concentraron los centros escolares y mas allá de los sectores privilegiados. De esa manera se podrá contar con fundamentos más sólidos para comprender la historia de la educación inicial en Nicaragua.

\section{Referencias bibliográficas}

Allen, A. T., (1989), “Vivamos con nuestros hijos": Los movimientos en defensa del jardín de infancia en Alemania y en Estados Unidos", 1840-1914, Revista de Educación, Mujer y Educación, 290, Septiembre-Diciembre, 113-134.

Allen, A. T., (1986), Jardines de niños. Jardines de Dios: Kindergarten y guarderías en Alemania en el Siglo XIX. Revista de Educación, 281, 125-154.

Ayerdis, M. (2004). Consumo, poder e identidad a finales del siglo XIX e inicios del XX en Nicaragua (una aproximación). Consultado en: www. ihnca.edu.ni Consultado el 6/6/15.

Arellano, J. E. (1999). Granada: aldea señorial. Managua: CIRA.

Baader, M. S. (2015). Modernizing early childhood education: The role of German women's movements after 1848 and 1968. En: Willikens, H. The Development of Early Childhood Education in Europe and North America. Londres: Palgrave Macmillan.

Barberena Pérez, A. (1974). Centenario del Instituto Nacional de Oriente. Managua: Imprenta Nacional.

Barnard, H. (1880). Barnard's American journal of education. Vol. XXX. Hartford: Office of American Journal of Education.

Bauernschuster, S. y Oliver, F., 2014, Culture, spatial diffusion of ideas and their long lasting imprints-evidence from Froebel's kindergarten movement. CESIFO. No. 4749. Consultado en: www.cesifo.org. Consultado el
6/11/15.

Bovalius, C. (1977). Viaje por Centroamérica 1881-1883. Managua: Editorial y Litografía San José. http:// memoriacentroamericana.ihnca.edu.ni

Campos Alba, L. (SF). Federico Froebel y la educación en México. Ponencia. XI. Congreso Nacional de Investigación Educativa/9. El Colegio Mexiquense A.C.

Coloma González, F. (1992). Biblioteca Nacional de Nicaragua. B. ANABAD, XL22. Núm.3-4. Consultadoen: dialnet. unirioja.es/descarga/articulo/224193.pdf

Cuadra Pasos, C. (1966). Cabos sueltos de mi memoria. Consultado en: http:// enriquebolanos.org

Donovan, J., (1883), Education in Nicaragua, Entrevista a Antonio Zambrana. Manuscrito. Biblioteca Bancroft, Universidad de Berkeley, California.

Froebel, F. (1932). Autobiografía. México: Universidad Nacional Autónoma de México. Sección Editorial. Consultada en: http://www.antorcha. net/biblioteca_virtual/pedagogia/ froebel/indice.html Consultada el 10/9/14.

García Menocal, A. (1886). Report of the US Nicaragua surveying party. http://www.archive.org/details/ reportusnicarag00deptgoog Consultado el 10/10/12.

Gobierno de Nicaragua, 4.12.1882, Acuerdo Aprobando unos Estatutos del Colegio de Señoritas de Granada, Capítulo 1o., Artículo 1. Consultado en: www. enriquebolanos.org Consultado el: $14 / 2 / 14$.

Gómez Carrillo, A. (1883). Instrucción pedagógica centro-americana. San Salvador: Tipografía La Concordia.

González, D. (1894). Primer Congreso Pedagógico Centroamericano. Consultado en: http://www.archive. org/details/primercongresope00guat Consultado el 10/10/12.

Guzmán, E. (1912). Diario Intimo. Managua: Tipografía Nacional. Consultado en: 
www.enriquebolanos.org Consultado el: $14 / 2 / 14$.

Hunt, Thomas y col. (2010). Encyclopedia of educational reform and dissent. Londres: Sage.

Lacayo, R. (1881), Carta a Padres de Familia, Solicitudes y diligencias varias, Legajo No. 459, Folio 250. 49-11. Archivo Municipal de Granada, Nicaragua.

López Miranda, M. (1988). Una chontaleña en la educación nacional. Biografía de Josefa Toledo de Aguerri. Juigalpa: Impresiones Técnicas.

Martí, J. (1902). En los Estados Unidos. Vol. III. Habana: Gonzalo de Quesada Editor.

Martínez Ruiz-Funes, M. J., (2012), Los catálogos de material de enseñanza como fuente para el estudio de la cultura material: la recepción y difusión del método Froebel en España, III Foro Ibérico de Museísmo Pedagógico, V Jornada Científica de la SEPHE. Consultado en: www. Congresos. um.es/fimupesephe/ Consultado el: 28/3/15.

Medina, F. (1883). Informe con que el Poder Ejecutivo de Nicaragua da cuenta al Congreso Nacional de sus principales actos en los ramos de relaciones exteriores, fomento e instrucción pública, durante el bienio de 1881-1882. Managua: Tipografía y Calle Nacional.

Morrison, G. (2005). Educación infantil. Madrid: Pearson, Prentice Hall.

Munchow, K. (2006). The relationship between the kindergarten movement, the movement for democracy and the early women's movement in the historical context of the revolution of 1848-49, as reflected in "Die FrauenZeitung". "History of Education", Vol. $35 \mathrm{~N} 2$.

Núñez, A. (1883). Organización de escuelas normales. Santiago: Imprenta de la Librería Americana.

Ossenbach Sauter, G. 1993, Estado y educación en América Latina a partir de su independencia (Siglos XIX y XX), "Revista Iberoamericana de
Educación", No. 1.

Peabody, Elizabeth, (1877), "Kindergarten Messenger", No. 1 y 2, Vol. 1. Cambridge: Peabody.

Peralta, M. V. (2009). Los primeros jardines infantiles en Latinoamérica. Primera parte: Los casos de Argentina, Nicaragua y Chile en el siglo XIX. Santiago: Gráfica LOM.

Puiggrós, A. (2003). ¿Qué pasó en la educación argentina? Buenos Aires: Kapelusz Editora.

Rodríguez Rosales, I. (1998). La educación durante el liberalismo: Nicaragua: 18931909. Managua: HISPAMER.

Rodríguez Rosales, Isolda (2006). Educación de las mujeres en el siglo XIX o la construcción de una identidad doméstica, Encuentro, Año XXXVIII, No. 73. 97-108.

Severino, A. J. (2007). Metodologia do trabalho científico. Sao Paulo: Cortez Editora.

Toledo de Aguerri, J. (1920). Carta de Roberto Lacayo a Jenaro Lugo, 17 de mayo de 1880. Revista Femenina Ilustrada. Managua: Tipografía Nacional.

Tyler Peabody Mann, M. y Palmer Peabody, E. (1870). Moral culture of infancy, and kindergarten guide. Nueva York: J. W. Schemerhorn \& Co.

United States Office of Education (1883). Report of the Federal Security Agency: Office of Education. Washington: United States Government Printing Office.

Upman, Charles, (1881), "The Kindergarten in the north-end industrial home, Boston", Frank Leslie's Illustrated Newspaper, V. 52, No. 1,340, June 4.

Wiebe, E. (1871). Kindergarten culture. Springfield: M. Bradley \& Co.

Wolfe, J. (2007). The Everyday Nation-State: Community and Ethnicity in NineteenthCentury. Lincoln: University of Nebraska Press.

Wollons, R. y col. (2000). Kindergartens $\mathcal{E}$ Cultures. The global diffusion of an idea. New Haven: Yale University Press. 